\title{
Effects of Lactoferrin on Subjective Skin Conditions in Winter: A Preliminary, Randomized, Double-Blinded, Placebo-Controlled Trial
}

This article was published in the following Dove Press journal: Clinical, Cosmetic and Investigational Dermatology

\author{
Hirotsugu Oda' \\ Momoko Miyakawa' \\ Masaru Mizuki² \\ Yuka Misawa ${ }^{3}$ \\ Teruomi Tsukahara ${ }^{2}$ \\ Miyuki Tanaka' \\ Koji Yamauchi' \\ Fumiaki Abe' \\ Tetsuo Nomiyama (1D) ${ }^{2}$ \\ 'Food Ingredients and Technology \\ Institute, R\&D Division, Morinaga Milk \\ Industry Co., Ltd, Zama, Kanagawa 252- \\ 8583, Japan; ${ }^{2}$ Department of Preventive \\ Medicine and Public Health, Shinshu \\ University School of Medicine, \\ Matsumoto, Nagano 390-862I, Japan; \\ ${ }^{3}$ Department of Rehabilitation, Nagano \\ Children's Hospital, Nagano 399-8288, \\ Japan
}

Correspondence: Hirotsugu Oda Food Ingredients and Technology Institute, R\&D Division, Morinaga Milk Industry Co., Ltd., 5-I-83, Zama, Kanagawa 252-8583, Japan

Tel +8I 462523045

Fax +8I 462523017

Email h-oda@morinagamilk.co.jp
Objective: To investigate the effects of lactoferrin (LF) on subjective skin conditions in winter.

Design: A preliminary, randomized, double-blinded, placebo-controlled trial.

Setting and subjects: Healthy adults in Japan.

Interventions: Intake of placebo, $200 \mathrm{mg}$, or $600 \mathrm{mg}$ of LF for 12 weeks in winter.

Endpoints: Changes in the scores of subjective skin conditions.

Results: Three hundred and forty-six subjects were randomized. Nine subjects (placebo, $\mathrm{n}=0 ; 200 \mathrm{mg}, \mathrm{n}=5 ; 600 \mathrm{mg}, \mathrm{n}=4$ ) withdrew consent, and 7 subjects (placebo, $\mathrm{n}=4 ; 200 \mathrm{mg}$, $\mathrm{n}=2 ; 600 \mathrm{mg}, \mathrm{n}=1$ ) were lost to follow-up, resulting in 330 for a full analysis set.

Outcomes: Changes in the scores of moisture were greater in the $600 \mathrm{mg}$ group than in the placebo group. Changes in the scores of moisture were greater in the $200 \mathrm{mg}$ and $600 \mathrm{mg}$ groups, and of texture were greater in the $600 \mathrm{mg}$ group than in the placebo group in female subjects.

Conclusion: Intake of LF may improve moisture or texture of skin in winter.

Keywords: lactoferrin, winter, skin, moisture, texture

\section{Introduction}

Cold and dry environmental conditions negatively affect the skin. People exposed to harsh weather during the winter may experience dry and itchy skin, or deterioration of already existing dermatoses. ${ }^{3}$ Major protective measures include moisturizing of the skin; ${ }^{6}$ however, other protective measures are insufficient and, thus, desired.

Lactoferrin (LF) is an iron-binding glycoprotein found in the milk of most mammals, ${ }^{8}$ and shows various biological functions. ${ }^{4}$ LF derived from bovine milk has been used to fortify food products and skin care products. ${ }^{14}$ In previous clinical trials, LF has been shown to improve dermatosis such as tinea pedis, ${ }^{16}$ acne vulgaris, ${ }^{2,7,9}$ plaque psoriasis, ${ }^{12}$ and atopic dermatitis. ${ }^{13}$ Therefore, intake of LF may be good for skin health. However, the effects of LF on the skin conditions of healthy people in winter have not yet been examined. Therefore, we herein preliminary investigated whether the intake of LF exerts positive effects on the subjective skin conditions of healthy adults in winter, as part of another trial to investigate the effects of LF on infectious diseases in winter.

\section{Materials and Methods}

Trial Design and Ethical Approval

This was a preliminary, randomized (1:1:1), double-blinded, placebo-controlled, parallel-group comparative trial conducted at the Department of Preventive 
Medicine and Public Health, Shinshu University School of Medicine, Matsumoto, Japan, between November 2015 and March 2016, in accordance with the current revision of the Declaration of Helsinki ${ }^{15}$ and Ethical Guidelines for Medical and Health Research Involving Human Subjects (2015). ${ }^{11}$ The protocol and informed consent form were approved by the Institutional Review Board (IRB) at Shinshu University School of Medicine on November 4, 2015 (approval number: 3271).

\section{Subjects, Eligibility, and Exclusion Criteria}

Eligible subjects were all healthy adults aged 20 years or more and working for kindergartens and nursery schools in Nagano prefecture, Japan. Exclusion criteria were a milk allergy, pregnancy, plan of resignation, a history of serious disorders in the liver, kidneys, heart, lungs, gastrointestinal tract, blood, endocrine system, or metabolic system, the habitual consumption of lactoferrin, and being judged as inappropriate to participate in this trial by the principal investigator (breast-feeding, chronic diseases, etc.).

\section{Intervention}

After IRB approval, investigators explained the details of this trial in accordance with the informed consent form, and written informed consent and background information were obtained from subjects. Three hundred and forty-six subjects were allocated into 3 groups. The test food and a diary were given before the start of the intervention. Subjects in each group were instructed to swallow 6 tablets per day (placebo, $200 \mathrm{mg}$ of LF, or $600 \mathrm{mg}$ of LF) with water at bedtime during the intervention period (12 weeks). Subjects were also instructed to record the intake of tablets, and physical changes in the diary. All subjects started and finished the intake of the test food and diary records on the same day. In the 7 days before (week 0) and in the last 7 days (week 12) of the intervention period, subjects answered questionnaires of subjective skin conditions. They subjectively evaluated moisture, resilience, texture, smoothness, transparency, pore, gloss, oiliness, wrinkle, and sag with scores between -3 (bad) and +3 (good). Changes in the scores of subjective skin conditions from week 0 to week 12 were calculated (Change in the score in each subjective skin condition $=$ score on week 12 - score on week 0 ).

\section{Endpoints}

The endpoints were the changes in the scores of subjective skin conditions. Adverse events were evaluated with
Revised National Cancer Institute - Common Toxicity Criteria (NCI-CTCAE) Version 4.0, and any adverse event for which a causal relationship to the intake of the test foods could not be ruled out was defined as an adverse drug reaction.

\section{Sample Size}

This trial was part of another trial to investigate the effects of LF on infectious diseases in winter. Therefore, we estimated the incidence of infectious diseases as $20 \%$, the expected intake of LF to reduce it to $6.7 \%$ (onethird) with a type 1 error of 0.05 and a power of $80 \%$, calculated a sample size of 306 (102 in each group), estimated a dropout rate of $33 \%$ (one-third), and set a target sample size of 450 (150 in each group) including dropouts.

\section{Randomization, Allocation, and Blinding}

The allocation manager, a researcher unrelated to this trial used computer-generated lists of random numbers blockrandomized with a block size of 3 (1:1:1 ratio), prepared allocation tables for each nursery schools and kindergartens, and numbered test foods consecutively in accordance with the lists. He concealed the allocation tables from investigators, sealed them in an opaque envelope, and kept them until code breaking, and investigators and subjects were blinded during this period. Investigators enrolled subjects, assigned order numbers to them, and gave test foods with the corresponding numbers to them. Test foods were round tablets with a red-orange color, a weight of $250 \mathrm{mg}$, a diameter of $9.1 \mathrm{~mm}$, and a thickness of $4.8 \mathrm{~mm}$. The tablet for the $600 \mathrm{mg}$ group contained $100 \mathrm{mg}(600 \mathrm{mg} / 6$ tablets $)$ of bovine LF (purity [ $\geq 96 \%$ ] by a HPLC method) derived from cheese whey (identical to the commercial supplement "Lactoferrin Original", Morinaga Milk Industry, Japan), while that for the $200 \mathrm{mg}$ group and placebo group contained $33.3 \mathrm{mg}$ ( $200 \mathrm{mg} / 6$ tablets) and $0 \mathrm{mg}$ of LF, respectively. The tablet for the $600 \mathrm{mg}$ group consisted of maltitol, indigestible dextrin, dextrin, hydrogenated rapeseed oil, LF, and guar gum. In the tablets for the $200 \mathrm{mg}$ group and placebo group, LF was replaced with dextrin, and the color tone was adjusted with pigment. The allocation manager evaluated the characteristics of tablets, including their appearance, solidness, smell, and taste, as well as the packages of the 3 types of test foods at both allocation and code breaking, and confirmed them to be indistinguishable. Code breaking was performed after locking of the database and statistical analysis plan. 
Table I Baseline Demographic of the Subjects

\begin{tabular}{|l|l|l|l|l|}
\hline & Total & Placebo & $\mathbf{2 0 0} \mathbf{~ m g}$ & $\mathbf{6 0 0} \mathbf{~ m g}$ \\
\hline Subjects, $\mathrm{n}$ & 346 & 116 & 113 & 117 \\
Female, \% & 95.1 & 94.0 & 93.8 & 97.4 \\
Age, year & 40.1 (12.9) & $40.3(13.2)$ & 40.4 (13.1) & $39.7($ I2.5) \\
\hline
\end{tabular}

Note: Age is shown as the mean (standard deviation).

\section{Statistical Analysis}

In accordance with the closed testing procedure, the MannWhitney $U$-test was used to analyze the changes in the scores of subjective skin conditions (the placebo group and the $600 \mathrm{mg}$ group were compared, and when a significant difference was observed between groups, the placebo group and the $200 \mathrm{mg}$ group were compared). The Jonckheere-Terpstra trend test was used to analyze the dose-response relationship. Statistical analyses were performed with EZR software (Saitama Medical Center, Jichi Medical University, Saitama, Japan). ${ }^{5} \mathrm{P}$ values $<0.05$ were considered to be significant.

\section{Results}

Three hundred and fifty subjects provided informed consent, 4 subjects were excluded ( 3 due to habitual consumption of lactoferrin and 1 due to being judged as inappropriate to participate), and a total of 346 subjects were enrolled (placebo, $\mathrm{n}=116 ; 200 \mathrm{mg}, \mathrm{n}=113 ; 600 \mathrm{mg}, \mathrm{n}=117$ ) (Table 1).

The mean (standard deviation [SD]) age was 40.1 years (12.9) and the proportion of females was 95.1\%. After randomization, 9 subjects withdrew consent, and 7 subjects were lost to follow-up. We used a full analysis set (FAS) of the data (330 subjects) for the primary analysis (Figure 1).

The pre-intervention period was between November and December 2015 (after IRB approval and trial registration). The intervention period was between December 2015 and March 2016 (12 weeks), and was completed as scheduled.

In the FAS of the data, 4, 7, and 5 subjects were lost in the placebo group, $200 \mathrm{mg}$ group, and $600 \mathrm{mg}$ group, respectively $(\mathrm{n}=112 ; \mathrm{n}=106 ; \mathrm{n}=112)$. The mean (SD) intake rates $(\%)$ of the test foods were 79.6 (18.7), 82.5 (20.3), and 82.7 (22.1) in each group, and were not significantly different $(\mathrm{p}=0.455)$. Baseline scores of subjective skin conditions in the FAS subjects are shown in Table 2. As endpoints, changes in the scores of moisture were significantly greater in the $600 \mathrm{mg}$ group than in the placebo group (Table 3). No significant differences were observed in other scores. As $95 \%$ of subjects were women, female subjects were also analyzed. Changes in the scores of moisture showed a significant trend, and were significantly greater in the $200 \mathrm{mg}$ and $600 \mathrm{mg}$ groups. Changes in the scores of texture were also significantly greater in the $600 \mathrm{mg}$ group than in the placebo group (Table 4).

The numbers of subjects with adverse events were 58, 68, and 64 in the placebo group, $200 \mathrm{mg}$ group, and $600 \mathrm{mg}$ group, respectively, and no significant differences were observed between groups $(\mathrm{P}=0.302)$. Major events included hay fever, menstrual pain, transient fatigue, and adverse drug reactions were not observed.

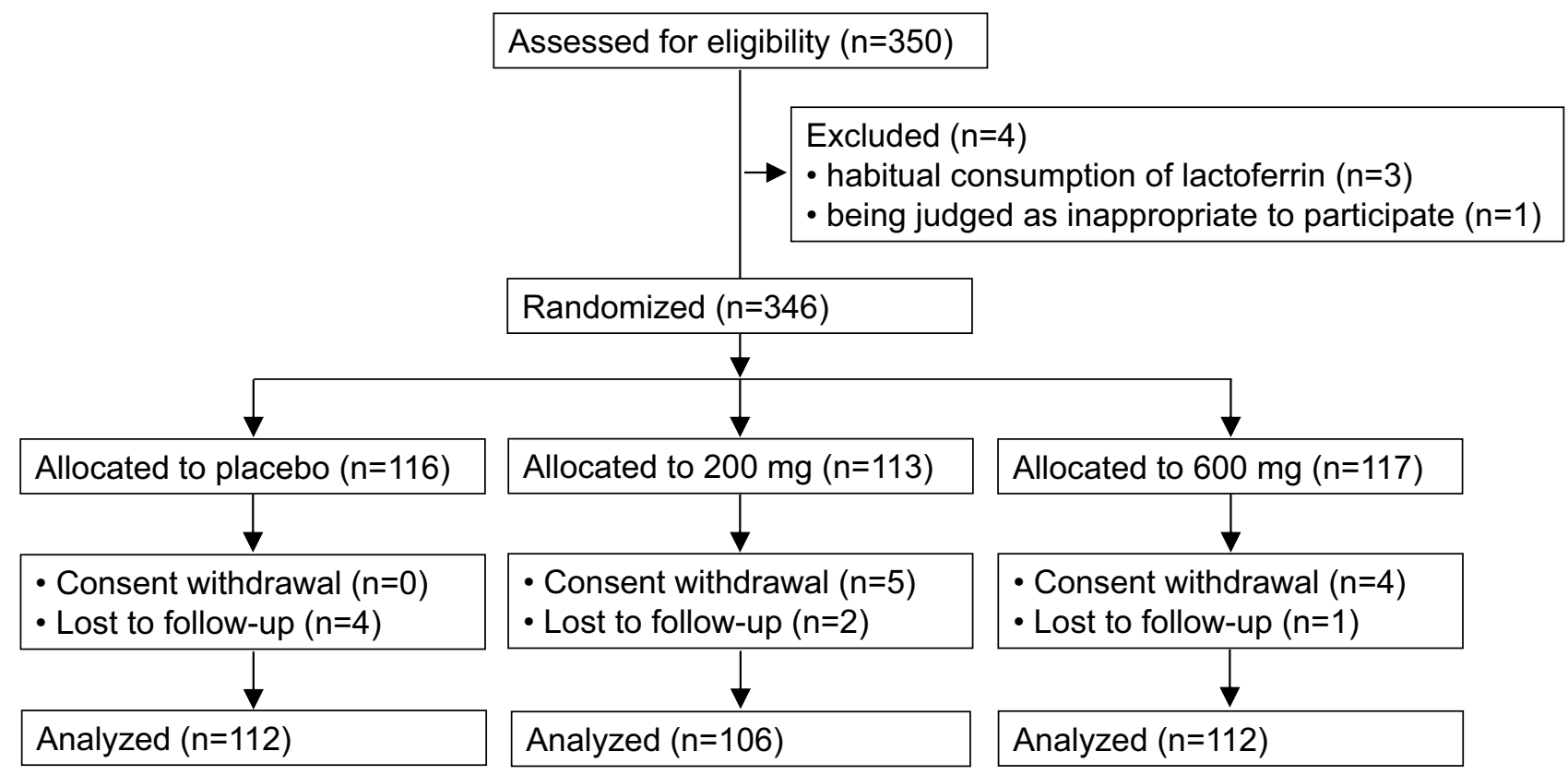

Figure I CONSORT flow diagram of subjects. 
Table 2 Baseline Scores of Subjective Skin Conditions in the FAS Subjects

\begin{tabular}{|c|c|c|c|}
\hline & Placebo & $200 \mathrm{mg}$ & $600 \mathrm{mg}$ \\
\hline Moisture & $-0.46(1.01)$ & $-0.38(1.20)$ & $-0.62(0.96)$ \\
\hline Resilience & $-0.66(1.11)$ & $-0.63(1.07)$ & $-0.79(0.99)$ \\
\hline Texture & $-0.72(1.05)$ & $-0.56(1.14)$ & $-0.78(0.91)$ \\
\hline Smoothness & $-0.44(1.13)$ & $-0.37(1.15)$ & $-0.45(0.91)$ \\
\hline Transparency & $-0.85(1.00)$ & $-0.70(1.10)$ & $-0.92(1.00)$ \\
\hline Pore & $-0.83(1.03)$ & $-0.88(0.98)$ & $-0.93(0.97)$ \\
\hline Gloss & $-0.71(1.04)$ & $-0.50(1.13)$ & $-0.76(0.88)$ \\
\hline Oiliness & $-0.30(0.88)$ & $-0.26(0.94)$ & $-0.43(0.86)$ \\
\hline Wrinkle & $-0.71(1.13)$ & $-0.68(1.07)$ & $-0.66(1.15)$ \\
\hline Sag & $-0.83(\mathrm{I} .1 \mathrm{I})$ & $-0.83(1.00)$ & $-0.74(1.10)$ \\
\hline
\end{tabular}

Note: Scores represent the mean (standard deviation).

\section{Discussion}

We herein investigated whether the intake of LF exerts positive effects on subjective skin conditions of healthy adults in winter. In Japan, almost all people working for nursery schools and kindergartens are women, therefore $95.1 \%$ of subjects were also women. In the FAS of the data, changes in the scores of moisture were significantly greater in the $600 \mathrm{mg}$ group than in the placebo group. In the analysis of female subjects, changes in the scores of moisture showed significant trend, and were significantly greater in the $200 \mathrm{mg}$ and $600 \mathrm{mg}$ groups, and changes in the scores of texture were also significantly greater in the $600 \mathrm{mg}$ group than in the placebo group. In a previous trial, the effects of LF on acne vulgaris were more clearly observed in women, and an association with the menstrual cycle was suggested. ${ }^{2}$ This may also be relevant to the results in the present trial. The incidence of adverse events was similar between groups, and adverse drug reactions were not observed. These results suggest that the intake of $200-600 \mathrm{mg} /$ day of LF is safe and efficacious for improving subjective skin conditions such as moisture and texture in healthy adults in winter.

In previous clinical trials, the effects of LF on skin illnesses were reported; $2,7,9,12,13,16$ however, this is the first report suggesting the positive effects of LF on skin conditions in health subjects.

In the present trial, scores of moisture and texture were improved in the LF group. LF is reported to suppress the

Table 3 Changes in the Scores of Subjective Skin Conditions in the FAS Subjects

\begin{tabular}{|c|c|c|c|c|c|c|}
\hline & Placebo & $200 \mathrm{mg}$ & $600 \mathrm{mg}$ & P Value ${ }^{a}$ & P Value $^{\text {b }}$ & $P$ for Trend \\
\hline Moisture & $0.21(1.02)$ & $0.41(0.99)$ & 0.49 (I.I5) & 0.092 & 0.048 & 0.064 \\
\hline Resilience & $0.30(1.06)$ & $0.40(1.03)$ & $0.55(1.04)$ & 0.393 & 0.064 & 0.077 \\
\hline Texture & $0.33(1.11)$ & $0.35(0.98)$ & $0.49(0.95)$ & 0.586 & 0.082 & 0.104 \\
\hline Smoothness & $0.22(1.15)$ & $0.26(1.11)$ & $0.37(1.03)$ & 0.869 & 0.389 & 0.414 \\
\hline Transparency & $0.35(1.09)$ & $0.39(0.91)$ & $0.47(1.02)$ & 0.859 & $0.57 I$ & 0.591 \\
\hline Pore & $0.39(0.93)$ & $0.47(1.05)$ & $0.48(1.00)$ & 0.731 & 0.688 & 0.710 \\
\hline Gloss & $0.36(1.13)$ & $0.33(1.11)$ & $0.49(0.97)$ & 0.883 & 0.148 & 0.195 \\
\hline Oiliness & $0.23(0.98)$ & $0.22(1.08)$ & $0.25(\mathrm{I} .12)$ & 0.847 & 0.914 & 0.912 \\
\hline Wrinkle & $0.31(0.98)$ & $0.32(1.01)$ & $0.24(1.02)$ & 0.870 & 0.695 & 0.725 \\
\hline Sag & $0.40(0.93)$ & $0.45(1.03)$ & $0.29(1.08)$ & 0.782 & 0.289 & 0.330 \\
\hline
\end{tabular}

Notes: Scores represent the mean (standard deviation). ${ }^{\text {aPlacebo vs }} 200 \mathrm{mg}$; ' placebo vs $600 \mathrm{mg}$.

Table 4 Changes in the Scores of Subjective Skin Conditions in Female Subjects

\begin{tabular}{|c|c|c|c|c|c|c|}
\hline & Placebo & $200 \mathrm{mg}$ & $600 \mathrm{mg}$ & P Value ${ }^{a}$ & P Value ${ }^{b}$ & P for Trend \\
\hline Moisture & $0.17(1.03)$ & $0.43(0.99)$ & $0.50(1.16)$ & 0.038 & 0.023 & 0.034 \\
\hline Resilience & $0.30(1.08)$ & $0.43(1.06)$ & $0.57(1.04)$ & 0.326 & 0.056 & 0.069 \\
\hline Texture & $0.32(1.13)$ & $0.37(1.00)$ & $0.51(0.95)$ & 0.385 & 0.046 & 0.063 \\
\hline Smoothness & $0.20(1.16)$ & $0.27(1.14)$ & $0.38(1.03)$ & 0.734 & 0.267 & 0.295 \\
\hline Transparency & $0.34(1.11)$ & $0.39(0.91)$ & $0.49(1.01)$ & 0.797 & 0.478 & 0.498 \\
\hline Pore & $0.39(0.95)$ & $0.48(1.07)$ & $0.50(0.99)$ & 0.677 & 0.628 & 0.655 \\
\hline Gloss & $0.36(1.14)$ & $0.35(1.14)$ & $0.5 \mathrm{I}(0.96)$ & 0.772 & 0.125 & 0.171 \\
\hline Oiliness & $0.23(0.97)$ & $0.20(1.10)$ & $0.25(1.13)$ & 0.927 & 0.893 & 0.891 \\
\hline Wrinkle & $0.31(0.98)$ & $0.33(1.02)$ & $0.25(1.02)$ & 0.949 & 0.760 & 0.785 \\
\hline Sag & $0.42(0.92)$ & $0.45(1.05)$ & $0.30(1.08)$ & 0.874 & 0.290 & 0.326 \\
\hline
\end{tabular}

Notes: Scores represent the mean (standard deviation). ${ }^{\text {PPlacebo vs }} 200 \mathrm{mg}$; ${ }^{\mathrm{b}}$ placebo vs $600 \mathrm{mg}$. 
increase of transepidermal water loss and reduction in skin hydration induced by UV irradiation in hairless mice. ${ }^{10}$ As the mechanisms of action, LF is considered to reduce IL- $1 \beta$ (inflammatory cytokine) levels enhanced by UV irradiation, and prevent skin damage. Inflammatory cytokine, IL- $1 \alpha$, is reported to be higher in the epidermis of hairless mice kept in a low-humidity environment. ${ }^{1}$ Therefore, the dry environment in winter may cause inflammation of skin and increase transepidermal water loss, which may be suppressed by LF.

This preliminary trial is part of another trial to investigate the effects of LF on infectious diseases in winter. The effects of oral LF were evaluated based on subjective scoring, and objective measures, such as skin moisture and transepidermal water loss, were not determined. In addition, the use of cosmetics, lotion, or cream was not also controlled. These are the limitations of the present study, and further studies that consider these limitations are required to confirm the reliability of the outcomes obtained herein.

\section{Conclusions}

The intake of LF improved subjective scores of skin moisture in healthy adults, and subjective scores of skin moisture and texture in women in winter. Further investigation using objective measures are needed to confirm the efficacy of LF for improving skin conditions in healthy subjects.

\section{Acknowledgments}

Authors thank all subjects, directors in kindergartens and nursery schools, municipal officials in Matsumoto-city, Ikedatown, Minowa-town, Yamagata-village, and Chikuhokuvillage, Matsumoto Regional Health Industry Promotion Council, and Matsumoto City Medical Association for contribution in this trial.

This study was registered at the University Hospital Medical Information Network (UMIN) Clinical Trials Registry in Japan on November 11, 2015 under the registration number UMIN000019752. Full details on the protocol and dataset used in the present study (in Japanese) are available from the corresponding author on reasonable request.

\section{Author Contributions}

All authors contributed to data analysis, drafting or revising the article, gave final approval of the version to be published, and agree to be accountable for all aspects of the work.

\section{Funding}

Morinaga Milk Industry provided research funds and the test foods.

\section{Disclosure}

HO, Momoko Miyakawa, MT, KY, and FA are employees of Morinaga Milk Industry. The authors report no other conflicts of interest in this work.

\section{References}

1. Ashida Y, Ogo M, Denda M. Epidermal interleukin-1alpha generation is amplified at low humidity: implications for the pathogenesis of inflammatory dermatoses. $\mathrm{Br} J$ Dermatol. 2001;144(2):238-243. doi:10.1046/j.1365-2133.2001.04007.x

2. Chan H, Chan G, Santos J, Dee K, Co JK. A randomized, double-blind, placebo-controlled trial to determine the efficacy and safety of lactoferrin with vitamin $\mathrm{E}$ and zinc as an oral therapy for mild to moderate acne vulgaris. Int J Dermatol. 2017;56(6):686-690. doi:10.1111/ijd.13607

3. Engebretsen KA, Johansen JD, Kezic S, Linneberg A, Thyssen JP. The effect of environmental humidity and temperature on skin barrier function and dermatitis. J Eur Acad Dermatol Venereol. 2016;30 (2):223-249. doi:10.1111/jdv.13301

4. García-Montoya IA, Cendón TS, Arévalo-Gallegos S, Rascón-Cruz Q. Lactoferrin a multiple bioactive protein: an overview. Biochimica Biophysica Acta Gen Subj. 2012;1820(3):226-236. doi:10.1016/j. bbagen.2011.06.018

5. Kanda Y. Investigation of the freely available easy-to-use software 'EZR' for medical statistics. Bone Marrow Transplant. 2013;48 (3):452-458. doi:10.1038/bmt.2012.244

6. Kikuchi K, Kobayashi H, Hirao T, Ito A, Takahashi H, Tagami H. Improvement of mild inflammatory changes of the facial skin induced by winter environment with daily applications of a moisturizing cream. Dermatology. 2003;207(3):269-275. doi:10.1159/000073089

7. Kim J, Ko Y, Park Y-K, Kim N-I, Ha W-K, Cho Y. Dietary effect of lactoferrin-enriched fermented milk on skin surface lipid and clinical improvement of acne vulgaris. Nutrition. 2010;26(9):902-909. doi:10.1016/j.nut.2010.05.011

8. Masson PL, Heremans JF. Lactoferrin in milk from different species. Comp Biochem Physiol. 1971;39(1):119-129.

9. Mueller EA, Trapp S, Frentzel A, Kirch W, Brantl V. Efficacy and tolerability of oral lactoferrin supplementation in mild to moderate acne vulgaris: an exploratory study. Curr Med Res Opin. 2011;27:793-797. doi:10.1185/03007995.2011.557720

10. Murata M, Satoh T, Wakabayashi H, Yamauchi K, Abe F, Nomura Y. Oral administration of bovine lactoferrin attenuates ultraviolet B-induced skin photodamage in hairless mice. J Dairy Sci. 2014;97 (2):651-658. doi:10.3168/jds.2013-7153

11. Ogasawara K. 8. Revised "ethical guidelines for medical and health research involving human subjects.". Jpn J Radiol Technol. 2017;73 (5):397-402. doi:10.6009/jjrt.2017_JSRT_73.5.397

12. Saraceno R, Gramiccia T, Chimenti S, Valenti P, Pietropaoli M, Bianchi L. Topical lactoferrin can improve stable psoriatic plaque. Giornale Italiano Di Dermatologia E Venereologia. 2014;149(3):335-340.

13. Tong PL, West NP, Cox AJ, et al. Oral supplementation with bovine whey-derived Ig-rich fraction and lactoferrin improves SCORAD and DLQI in atopic dermatitis. J Dermatol Sci. 2017;85(2):143-146. doi:10.1016/j.jdermsci.2016.11.009

14. Wakabayashi H, Yamauchi K, Takase M. Lactoferrin research, technology and applications. Int Dairy J. 2006;16(11):1241-1251. doi:10.1016/j.idairyj.2006.06.013

15. World Medical Association Declaration of Helsinki. Ethical principles for medical research involving human subjects. JAMA. 2013;310 (20):2191. doi:10.1001/jama.2013.281053

16. Yamauchi H, Yamazaki W, Kuwata T, Yamaguchi H. Oral administration of bovine lactoferrin for treatment of tinea pedis. A placebo-controlled, double-blind study. Mycoses. 2000;43(5):197-202. doi:10.1046/j.14390507.2000.00571.x 


\section{Publish your work in this journal}

Clinical, Cosmetic and Investigational Dermatology is an international, peer-reviewed, open access, online journal that focuses on the latest clinical and experimental research in all aspects of skin disease and cosmetic interventions. This journal is indexed on CAS.
The manuscript management system is completely online and includes a very quick and fair peer-review system, which is all easy to use. Visit http://www.dovepress.com/testimonials.php to read real quotes from published authors.

Submit your manuscript here: https://www.dovepress.com/clinical-cosmetic-and-investigational-dermatology-journal 